\title{
СИСТЕМА РАБОТЫ ПО РАЗВИТИЮ РЕЧЕМЫСЛИТЕЛЬНОЙ ДЕЯТЕЛЬНОСТИ ЧЕРЕЗ АКТУАЛИЗАЦИЮ ОБРАЗНЫХ ПРЕДСТАВЛЕНИЙ У ДЕТЕЙ 5-7 ЛЕТ С РЕЧЕВЫМИ НАРУШЕНИЯМИ
}

Рохман Е.H. учитель-логопед высшей категории

Развитие речемыслительной деятельности у дошкольников и младших школьников - обязательный и неотъемлемый процесс преодоления речевых нарушений. Как часто мы видим детей, которые научились произносить все звуки, достигнув желанной «вершины» в виде звука Р, научились строить фразы, выделять «лишний» предмет, обобщать различные знакомые понятия, достаточно успешно систематизировать предложенные рисунки, предметы и т.п. Да, мы их этому научили. Но стоит ребенку задать вопрос, который связан с мысленными образами, не подкрепленными картинками, попросить второклассника решить задачу, как сразу становится ясно, что ребенок недостаточно понял нас. А, может, и вовсе не понял. Глазки не «горят».

Попробуйте произнести на подгрупповом занятии в старшей группе для детей с ТНР слово «машина», например, и сразу спросите: «Какую машину вы себе представили?» Большинство детей-логопатов с удивлением ответит: «Никакую...»

Мои многолетние наблюдения за дошкольниками и младшими школьниками показали, что зрительные образы у них сформированы очень неполно, иногда искаженно. Детям сложно осмыслить многоступенчатую инструкцию, найти скрытый смысл фразы. «А вы покажите нам картинку, тогда мы все поймем», - сказали мне однажды воспитанники подготовительной к школе группы.

С момента этой фразы прошло много лет. Это время было посвящено разработке и совершенствованию методических приемов для развития речемыслительной деятельности с помощью актуализации зрительных представлений. Системой этой работы хотелось бы поделиться в данной статье.

Установлено, что за работу логических схем отвечает левое полушарие. Там же «находятся» наши слова, которые синхронизируются в процессе речи с образами, живущими в правом полушарии. Но, к сожалению, часто именно уровень этой синхронизации у детей с ТНР недостаточен. Почему? Рискну ответить: мы так много работаем над развитием левого полушария, что, в 
конце концов, это приводит к подавлению правого, которое заведует целостным восприятием действительности, восприятием музыки, художественных образов. Система моей работы по развитию речемыслительной деятельности начинается с предметных картинок. Только эти картинки рисуют сами дети. Каждая лексическая тема может «дать» материал для рисования. Прошу детей закрыть глаза и ответить мне, какую, например, игрушку они «увидели». Чаще всего приходится ждать на несколько секунд дольше, чем мы (взрослые) предполагаем, пока малыши «увидят» нужный образ. Это сразу видно по их мимике, даже при закрытых глазках. Ответы бывают разными, но обязательно на лицах детей сквозит удивление: оказывается, что они могут «видеть» то, чего воочию перед ними нет! Именно с этого простого момента и начинается работа по стимуляции правого полушария. В нашей жизни появляется игра под названием «Нарисуй мои мысли». Цель этой работы - приучить детей к мысли, что каждое слово значимо, и это можно мысленно представить и нарисовать на листе.

\section{ПЕРВЫЙ ЭТАП. ВКЛЮЧЕНИЕ ВООБРАЖЕНИЯ.}

Как уже отмечалось выше, работу начинаем с рисования предметных картинок (рисуем простым карандашом, чтобы не застревать на малозначимых деталях). Предлагаю малышам:

- Нарисуйте, пожалуйста, МЯЧИКИ (к примеру).

Кто-то сразу берется за дело, а кто-то спрашивает:

- А сколько? Вы не сказали, сколько?

- Сколько хочешь, лишь бы у тебя получились МЯЧИКИ.

- Можно я нарисую ДВА? - спрашивает один ребенок.- Можно.

-А можно пять? - спрашивает второй.

И вот тут приходит момент для включения речемыслительных процессов. Я говорю:

- Да, мои хорошие, можно два, можно пять, можно десять, если будет время, но нельзя нарисовать мячик ОДИН. Ведь я сказала «мячикИ»!

Такие упражнения проводятся на каждом подгрупповом занятии, занимают не более пяти минут. Через некоторое время предметы можно рисовать и с четким указанием количества таковых.

Похожая работа проводится на этапе знакомства с понятием «слово». Ведь слово имеет смысл. Его можно нарисовать. А как нарисовать ША?

- Шапка! - восклицают дети.

- Я не сказала «шапка». Я сказала только ША. 
- Это нельзя нарисовать, потому что не понятно, - следует вывод детей.

- Значит, ША - это НЕ СЛОВО.

В таком ключе работа над понятиями «слово» - «не слово» идет очень эффективно. Конечно, для формирования внутреннего чувства слова мы рисуем предметы, исключая существительные, обозначающие эмоции и т.п. Но, владея переносом, дети быстро осознают то, чего мы от них ждем.

\section{ВТОРОЙ ЭТАП. РИСОВАНИЕ ОДНОСЮЖЕТНЫХ КАРТИНОК.}

Мои «мысли» превращаются в задания типа:

- На квадратном коврике лежат мячики.

- На круглом коврике лежит кубик.

Полученные рисунки мы обсуждаем сразу. Ошибочные варианты корректируются мною на глазах у детей. Это очень важно - не откладывать исправление на «потом», т.к. иначе заданный образ гаснет и теряет свою актуальность. Очень скоро наступает время, когда рисование «мыслей» становится неотъемлемой частью каждого занятия. Дети так и говорят: «А давайте рисовать для ума!».

Для примера приведу примеры фраз, используемых для рисования:

$\checkmark$ Из-за темной тучи выглянул месяи.

$\checkmark$ Под березой находились муравейники.

$\checkmark$ Около портфеля лежал учебник.

$\checkmark$ Под самым окном росла развесистая береза.

$\checkmark$ Сквозь облака светила луна.

$\checkmark$ Мальчик выше девочки.

$\checkmark$ Над иветком порхали бабочки.

$\checkmark$ На салфетку поставили корзину с ягодами.

$\checkmark$ На круглом столе лежала толстая открытая книга.

$\checkmark$ На протянутой между деревьями веревке сушатся два полосатых полотения.

$\checkmark$ Гибкие ветки деревьев качались под сильными порывами ветра.

$\checkmark$ На вершине пологого холма виднелась небольшая деревенька.

$\checkmark$ Налево за густым кустом начинались отчетливые волчьи следы.

$\checkmark$ Возле маленького домика росли вьющиеся по забору пышные розы.

$\checkmark$ По каменной дороге торопятся четьре ослика.

$\checkmark$ Ветки сирени стояли в пузатом кувшине на подоконнике. 
$\checkmark$ На круглом столе, покрытом скатертью, стояла ваза с иветами и блюдо с яблоками.

$\checkmark$ Из-под высокого шкафа, двериа которого была приоткрыта, выглядывал щенок.

Сложность сюжета фразы, ее распространенность выбираю в зависимости от контингента воспитанников, их возраста и тяжести речевых нарушений. Самая главная цель моей работы - научить ценить слово, удерживать объем фразы, не терять мысль во время рисования. Хочу показать примеры детских работ. Это только на первый взгляд кажется, что ничего сложного в такой работе нет. Ошибки в детских рисунках очень четко демонстрируют нам $u x$ мысли, ux понимание. Другого способа «увидеть» образное мышление наших воспитанников у нас нет. Ведь если мы спросили ребенка, все ли он понял, а он ответил утвердительно, то это вовсе не означает, что он понял именно то, что мы от него ждем.

Итак, рисунки детей. Проанализировав их внимательно, становится понятно, как много недочетов можно увидеть в работе их правых полушарий. Дети не придают значения прилагательным, не понимают многие речевые обороты, затрудняются в удержании в памяти имен числительных.

Над трехэтаэным домом взошла полная луна. (Рис. 1,2,3)

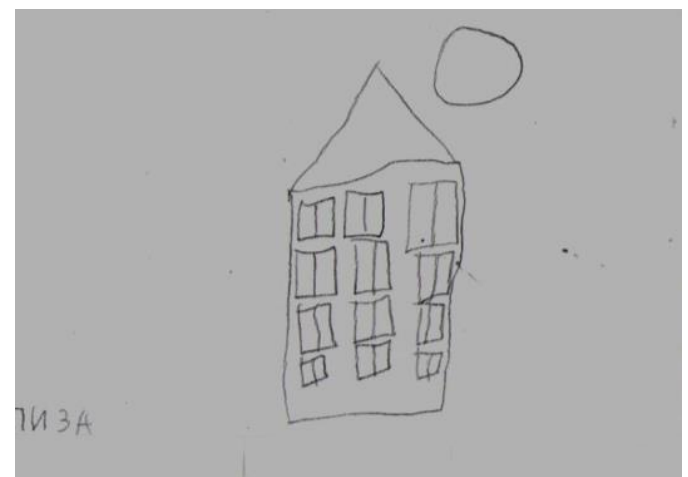

Рис. 1

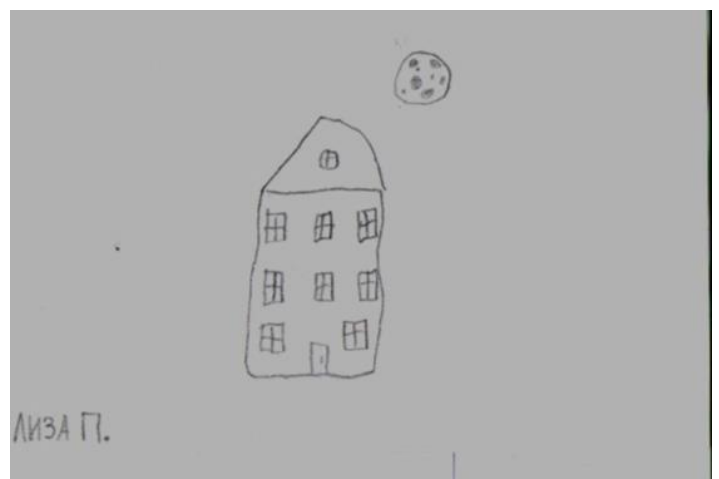

Рис. 2

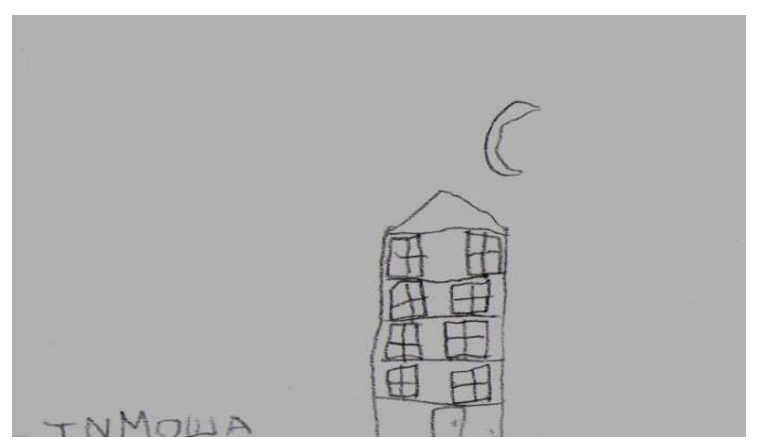

Рис. 3 
В одном из окон появилась коика. (Рис. 4,5,6)

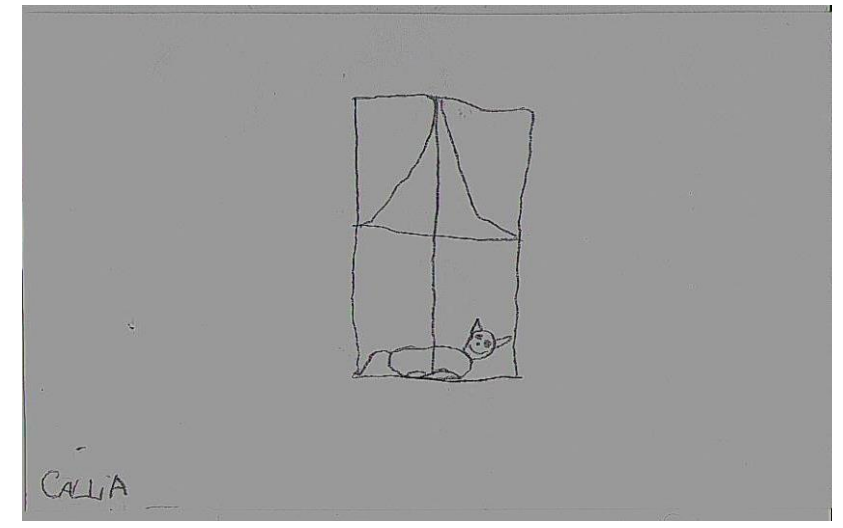

Pис. 4

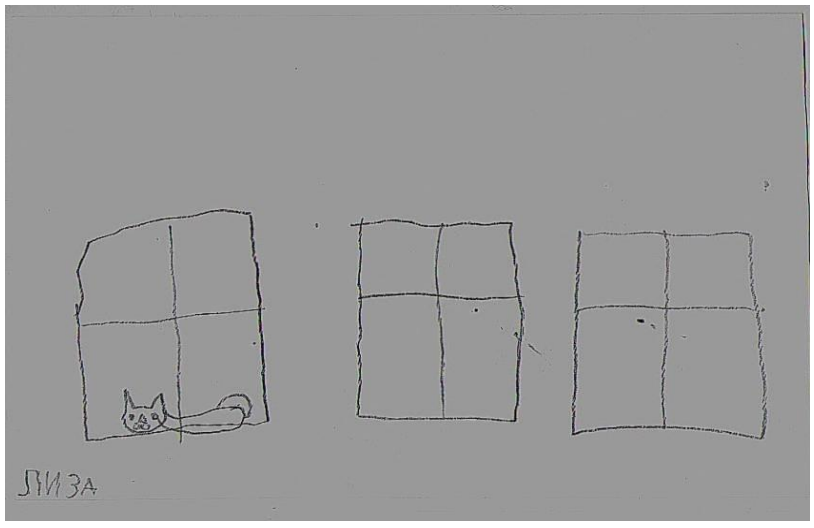

Puc. 5

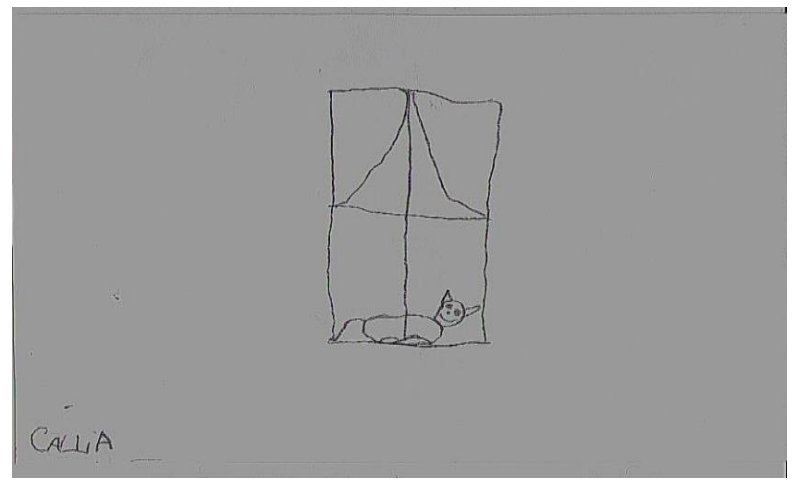

Pис. 6

Под, елкой украшенной тремя шарами, сидит полосатая кошка. (Рис.7, 8, 9)

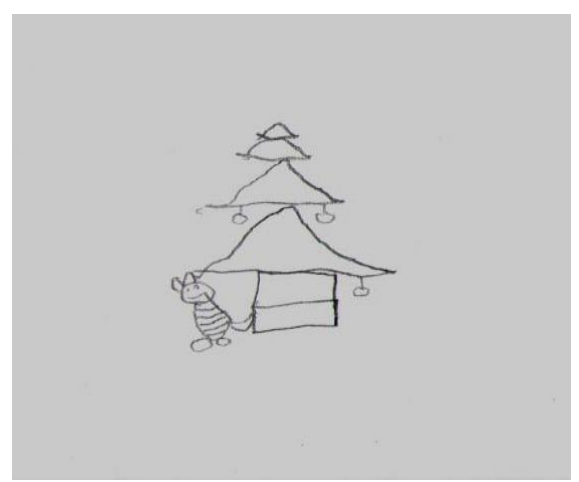

Pис. 7 


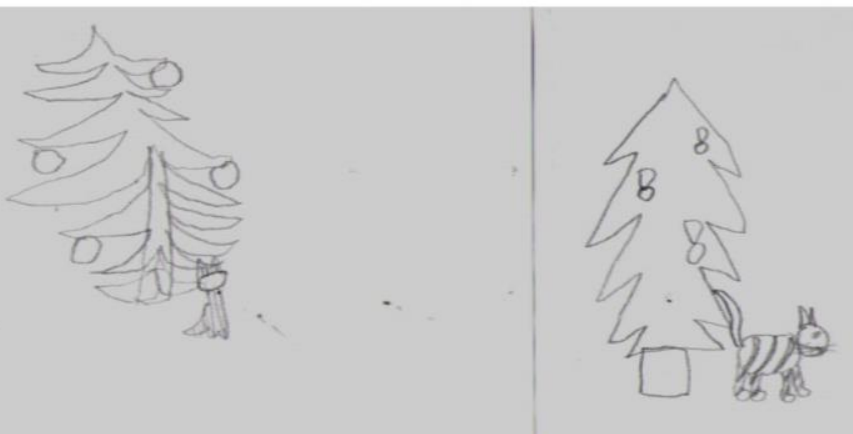

Pис. 8

Рис. 9

Справа от икафа стоит круглый стол, на котором находится ваза с цветком. (Рис. 10,11,12,13)

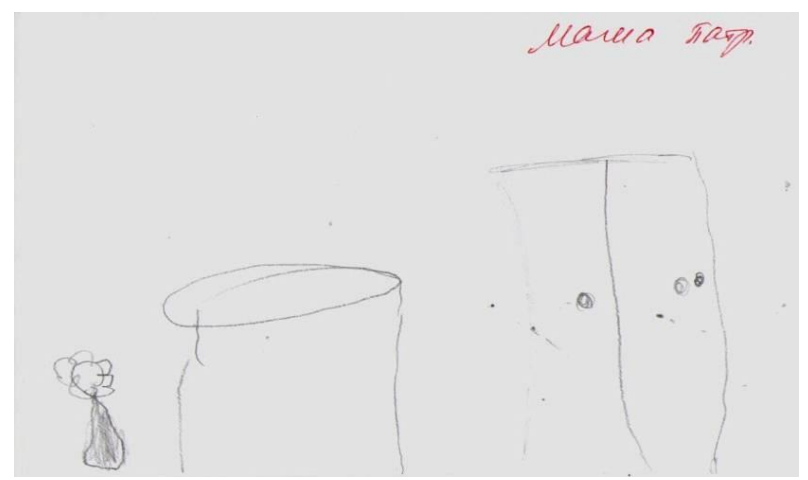

Рис. 10

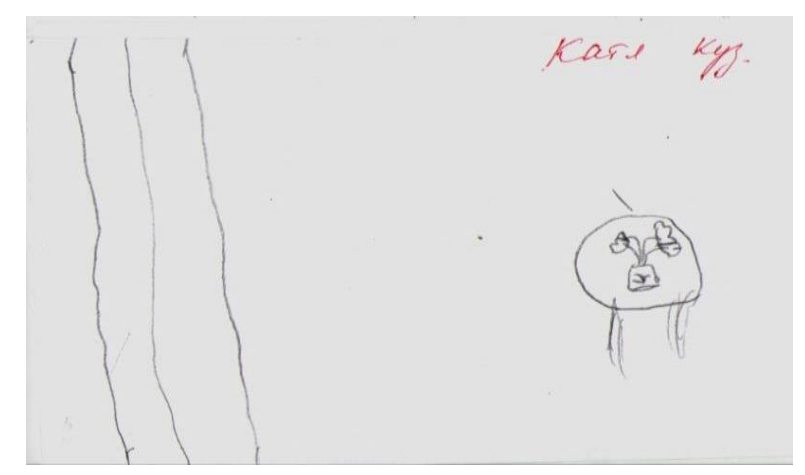

Рис. 12

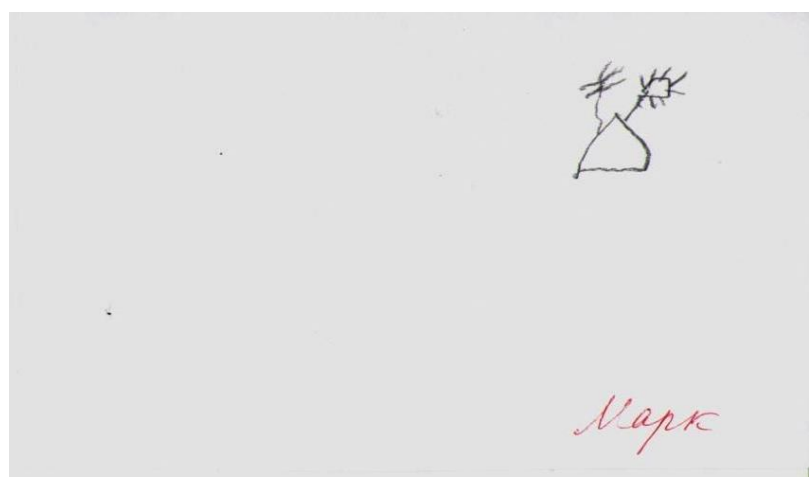

Pис. 11

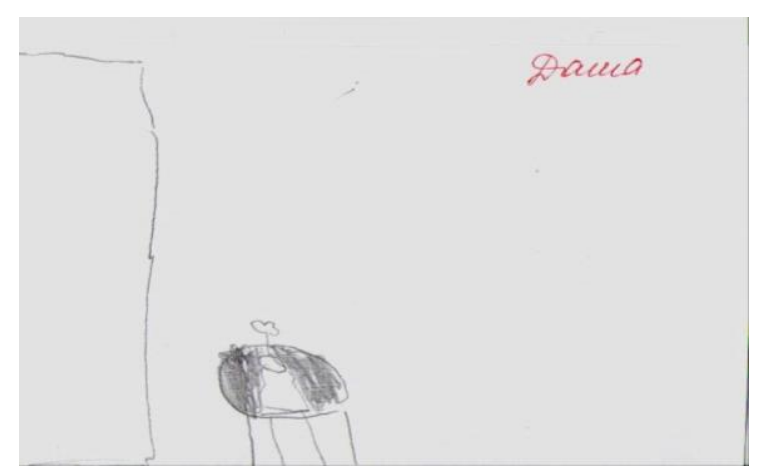

Рис. 13

Солнечным днем ребята наблюдали, как по ручейку пльвет кораблик. (Рис. 14,15,16) 


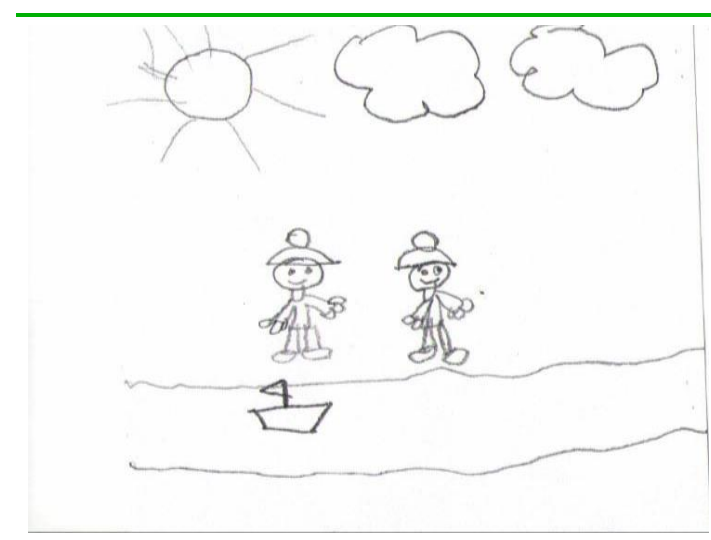

Рис. 14

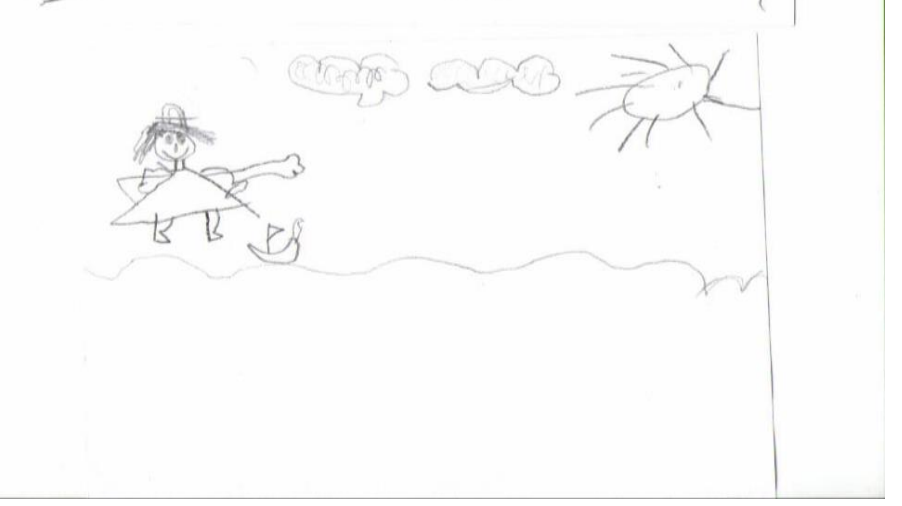

Рис. 15

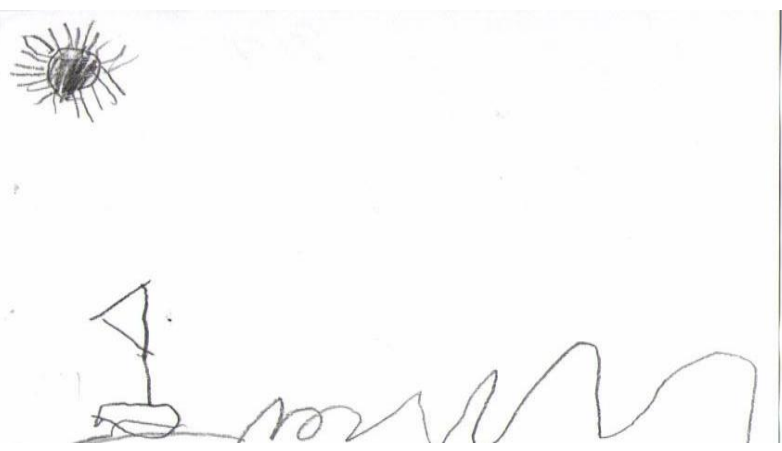

Рис. 16

Если внимательно рассмотреть представленные фрагменты, то несложно заметить несоответствие рисуночных ответов заданным фразам. В каждой серии среди данных рисунков только один правильный.

На занятиях ошибки встречаются постоянно. Но, повторюсь, исправлять их необходимо сразу.

После нарисованных заданий следует обязательное проговаривание детьми «нарисованных мыслей». Это тоже сначала очень трудно, но со временем детские фразы становятся все увереннее, а самое главное преодолеваются различные аграмматизмы. Проговаривая фразу, дети необыкновенно четко, даже несколько замедленно произносят окончания каждого слова, что, согласитесь, очень трудно добиться от них в обычной речевой работе.

\section{ТРЕТИЙ ЭТАП. РИСУЕМ КАРТИНКИ С ОТЛИЧИЯМИ}

Рисование серий из «мыслей». Для примера:

- За кораблЯМИ плывЁТ дельфиН.

- За кораблЯМИ плывУТ дельфинЫ.

- З За дельфинАМИ плывУТ кораблИ. 
- З За дельфинОМ плвЁТ корабЛь.

Нарисовали. Проверили. Озвучили. Этот этап работы длится в течение всего предшествующего школе года.

\section{ЧЕТВЕРТЫЙ ЭТАП. ФОРМИРОВАНИЕ ПРОЦЕССОВ ОСОЗНАННОГО ЧТЕНИЯ}

С момента, когда дети начинают самостоятельно читать первые слова, тоже используется прием рисования. Рядом с прочитанным словом всегда прошу нарисовать представленную картинку. (Рис. 17)

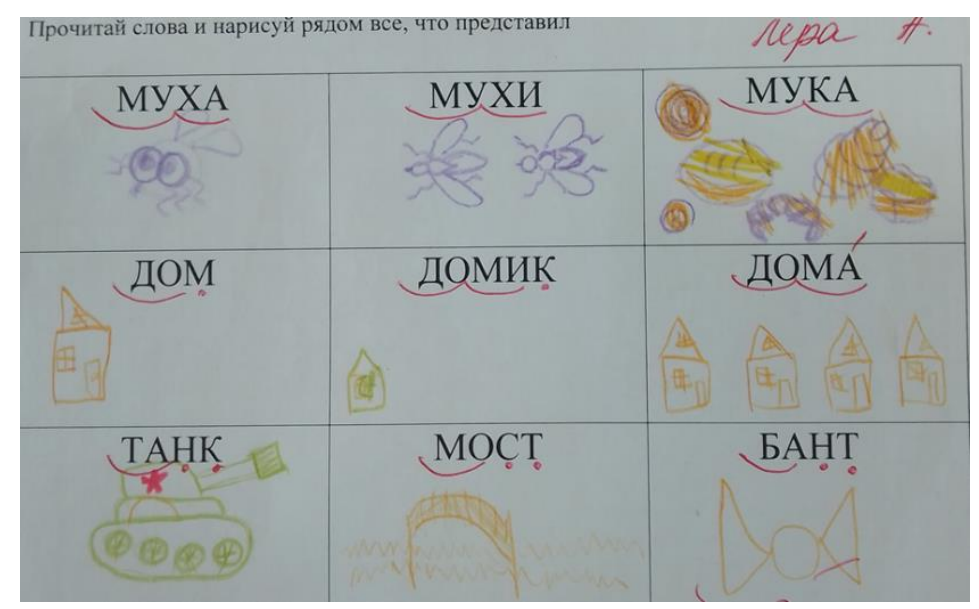

Рис. 17

Обязательно выполняются рисунки к предложениям типа:

Вот мама и Маша. У мамы бусы. У мамы сумка. У Маши банты и банан. (Рис. 18)

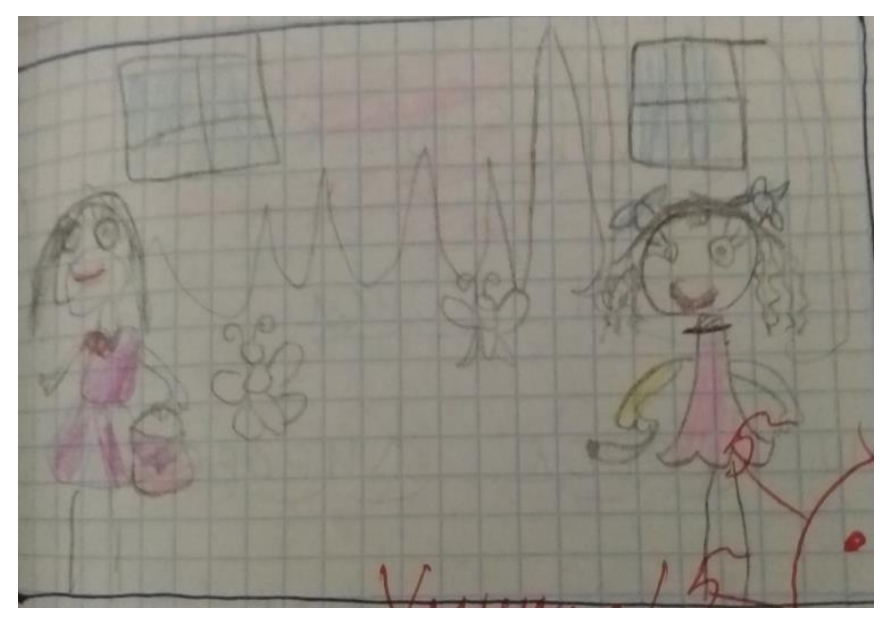

И, конечно, выполняются рисунки к сериям фраз с различиями. (Рис. $19,20)$ 

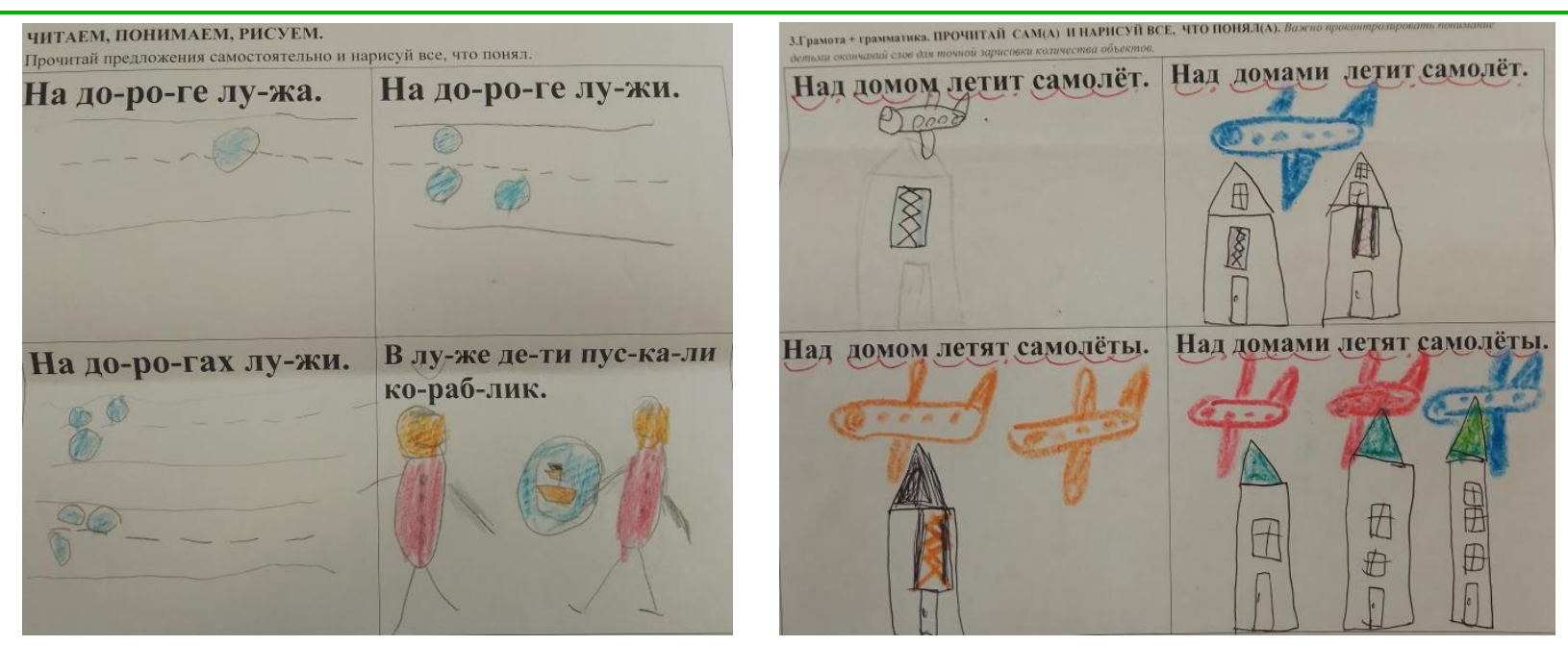

Во время рисования дети сразу понимают, что читают они не ради процесса или прихоти взрослых. Читают они ради информации. Такая работа нравится и родителям, т.к. они сразу видят результаты обучения своих малышей.

Необходимо отметить также развитие и совершенствование у детей процессов анализа любой воспринимаемой ими информации. Это выражается в постоянных многочисленных детских вопросах во время чтения художественной литературы. К концу подготовительной группы дети никогда не оставляют для себя что-либо непонятым. Согласитесь, что дети с речевыми нарушениями часто не задают никаких вопросов вообще.

Обязательно следует отметить, что работа над актуализацией образных представлений очень важна и в начальной школе. Поскольку по статистике в первый класс поступает до $60 \%$ детей с речевыми нарушениями. Недостаточность речемыслительной деятельности у них очень быстро дает себя знать при решении текстовых задач. Педагоги начальной школы тщетно бьются за успехи этих детей, но результатов нет. И это не потому, ребенок не умеет слагать или вычитать. Нет. Это потому, что он не может представить себе эту задачу, как бытовую ситуацию в «картинке». По своему опыту работы с младшими школьниками в том числе, могу с уверенностью утверждать, что приемы по визуализации представлений способствуют развитию умения решать текстовые задачи.

Эта же работа необходима в обучении школьников пересказам и изложениям. Нам трудно представить, но дети с речевыми нарушениями не «видят» событий текста в своем воображении. Работу правого полушария для них приходится открывать, как неожиданную способность. Но результаты не заставляют себя долго ждать. 
Следует отметить, что и социальная адаптация ребенка напрямую зависит от уровня сформированности речемыслительных операций, обеспечивающих развертывание мысли во внешней речи. Созданная мною система работы всецело содействует успешной социализации и обучению дошкольников и младших школьников.

Проводимая работа демонстрирует свою стопроцентную эффективность в динамике коррекции различных речевых нарушений. Результатами ее являются следующие аспекты:

- стимулирование работы правого полушария;

- стимулирование развития межполушарных связей;

- расширение объема слухоречевой памяти;

- развитие речемыслительной деятельности;

- развитие связной речи, логического мылиления;

- формирование понятия «слово»;

- усвоение многих грамматических конструкций;

- формирование понятий морфологии;

- стимулирование критичности мышления;

- повышение любознательности;

- интерес к слушанию чтения взрослых и собственному чтению;

- совершенствованию процессов логического анализа;

- развитие социальной адаптации.

\section{Список литературы}

1. Восприятие речи. Вопросы функциональной ассиметрии мозга. В.П. Морозов, И.А. Вартанян, В.И. Галунов - Л.: Наука, 1998 г.

2. Мышление и речь. Выготский Л.С. Собр.соч. - т.2, 1982, с.5-361

3. Анализ смысловой стороны речи детей 5-7 лет. Ахутина Т.В., Засыпкина И.В., Романова А.А. - Школа здоровья. - 2007. - №2

4. Функциональная ассиметрия мозга в организации речевой деятельности. Балонов Л.Я., Деглин В.Л., Черниговская Т.В.-Л.: Наука, 1985г. 